\title{
Exome sequencing study of 20 patients with high myopia
}

\author{
Ling Wan ${ }^{1,2}$, Boling Deng ${ }^{2}$, Zhengzheng Wu ${ }^{2}$, Xiaoming Chen ${ }^{\text {Corresp. } 2}$ \\ 1 Department of Ophthalmology, West China Hospital, Sichuan University, Chengdu, Sichuan, China \\ Electronic Science and Technology, Chengdu, Sichuan, China \\ Corresponding Author: Xiaoming Chen \\ Email address: chenxm058@163.com
}

Background. High myopia is a common ocular disease worldwide. To expand our current understanding of the genetic basis of high myopia, we carried out a whole exome sequencing study to identify potential causal gene mutations.

Methods. A total of 20 individuals with high myopia were exome sequenced. A novel filtering strategy combining phenotypes and functional impact of variants was applied to identify candidate genes by multi-step bioinformatics analyses. Network and enrichment analysis were employed to examine the biological pathways involved in the candidate genes.

Results. In 16 out of 20 patients, we identified 20 potential pathogenic gene variants for high myopia. 18 variants were located in myopia-associated chromosomal regions. In addition to the novel mutations found in 5 known myopia genes (ADAMTS18, CSMD1, P3H2, RPGR, and SLC39A5), we also identified pathogenic variants in 7 ocular disease genes (ABCA4, CEP290, HSPG2, PCDH15, SAG, SEMA4A, and $U S H 2 A$ ) as novel candidate genes. The biological processes associated with vision were significantly enriched in our candidate genes, including visual perception, photoreceptor cell maintenance, retinoid metabolic process, and cellular response to zinc ion starvation.

Discussion. Systematic mutation analysis of candidate genes was performed using whole exome sequencing (WES) data, functional interaction ( $\mathrm{FI}$ ) network, GO and pathway enrichment. Fl network analysis revealed important network modules and regulator linker genes (EP300, CTNNB1) potentially related to high myopia development. Our study expanded the list of candidate genes associated with high myopia, which increased the genetic screening performance and provided implications for future studies on the molecular genetics of myopia. 


\section{Exome sequencing study of 20 patients with high myopia}

2 Ling Wan ${ }^{1,2}$, Boling Deng ${ }^{2}$, Zhengzheng $\mathrm{Wu}^{2}$, Xiaoming $\mathrm{Chen}^{2 \#}$

$3{ }^{1}$ Department of Ophthalmology, West China Hospital, Sichuan University, Chengdu, Sichuan, China

42 Department of Ophthalmology, Sichuan Academy of Medical Sciences, Sichuan Provincial People's Hospital

5 and Affiliated Hospital of University of Electronic Science and Technology, Chengdu, Sichuan, China

6

7 \#Corresponding Author:

8 Xiaoming Chen ${ }^{2}$

9 32\# W. Sec 2, 1st Ring Rd. Chengdu, Sichuan, 610072

10 China

11 Email address: $\underline{\text { chenxm58@,163.com }}$ 


\section{Abstract}

Background. High myopia is a common ocular disease worldwide. To expand our current understanding of the genetic basis of high myopia, we carried out a whole exome sequencing study to identify potential causal gene mutations.

Methods. A total of 20 individuals with high myopia were exome sequenced. A novel filtering strategy combining phenotypes and functional impact of variants was applied to identify candidate genes by multi-step bioinformatics analyses. Network and enrichment analysis were employed to examine the biological pathways involved in the candidate genes.

Results. In 16 out of 20 patients, we identified 20 potential pathogenic gene variants for high myopia. 18 variants were located in myopia-associated chromosomal regions. In addition to the novel mutations found in 5 known myopia genes (ADAMTS18, CSMD1, P3H2, RPGR, and $S L C 39 A 5)$, we also identified pathogenic variants in 7 ocular disease genes (ABCA4, CEP290, $H S P G 2, P C D H 15, S A G, S E M A 4 A$, and USH2A) as novel candidate genes. The biological processes associated with vision were significantly enriched in our candidate genes, including visual perception, photoreceptor cell maintenance, retinoid metabolic process, and cellular response to zinc ion starvation.

Discussion. Systematic mutation analysis of candidate genes was performed using whole exome sequencing (WES) data, functional interaction (FI) network, GO and pathway enrichment. FI network analysis revealed important network modules and regulator linker genes (EP300, $C T N N B 1$ ) potentially related to high myopia development. Our study expanded the list of candidate genes associated with high myopia, which increased the genetic screening performance and provided implications for future studies on the molecular genetics of myopia.

\section{Introduction}

Myopia, recognized as the most common ocular disease (Holden et al. 2016; Shi et al. 2011; Vitale et al. 2009), has a prevalence of 20-30\% Australians, Americans and Western European populations (Kempen et al. 2004). One extreme type of myopia is high myopia, defined as a refractive error of at least -6.0 diopters (D) or axial length $>26 \mathrm{~mm}$ (Young et al. 1998). It occurred in about $2.7 \%$ of the world population in 2000 and showed significant increase in prevalence over the last 2 decades (Holden et al. 2016). Although myopia is usually a benign disorder that can get a good vision correction by glasses and contact lenses, patients with high myopia are at increased risk of other complications, such as cataract, glaucoma, retinal detachment (RD), and posterior staphyloma (Morgan et al. 2012; Saw et al. 2005; Xu et al. 2006). Genetic factors play a critical role in the development of high myopia based on family aggregation and twin studies (Hammond et al. 2001; Katz et al. 1997), with its heritability estimated to be over 70\% in large twin studies (Dirani et al. 2006; Lopes et al. 2009). Family linkage studies have identified 26 Quantitative Trait Loci (QTLs) (OMIM: 160700) so far (Andrew et al. 2008; Li et al. 2009; Nakanishi et al. 2009; Schwartz et al. 1990; Young et al. 1998). However, only 7 QTLs are fine-mapped to the causal genes (Table S1), a large proportion 
51 of linkage signal found in family studies still remain to be elucidated.

52 The inheritance mode for familial form of high myopia is complex. It may be inherited in an 53 autosomal recessive, autosomal dominant, or X-linked recessive manner ( $\mathrm{Ng}$ et al. 2009; Zhang

54 2015). Quite a few disease-associated genes have been identified in individual studies, such as dominant genes SCO2 (Tran-Viet et al. 2013), ZNF644 (Shi et al. 2011) and P4HA2 (Guo et al. 2015); recessive genes LRPAP1 (Aldahmesh et al. 2013) and LEPREL1 (Mordechai et al. 2011); X-linked gene $A R R 3$ (Xiao et al. 2016). As the sequencing costs keep dropping, whole-exome sequencing (WES) has been gradually adopted in studies of familial or early-onset high myopia. Variants in LRPAP1, CTSH, LEPREL1, ZNF644, SLC39A5, and SCO2 genes were comprehensively screened in 298 families with early-onset high myopia (Jiang et al. 2014). However, only a small proportion of patients were found to have deleterious mutations in these 6 genes. Sun et al. (Sun et al. 2015) investigated mutations in 234 genes associated with retinal dystrophies in 298 patients with early-onset high myopia. They found that 34 of 234 genes had potential pathogenic mutations including GNAT1, GUCY2D, COL2A1, COL11A1, PRPH2, FBN1, TSPAN12, CACNA1F, OPA1, PAX2 and RPGR. Recently, Kloss et al. (Kloss et al. 2017) analyzed 14 families of high myopia through WES combining with QTL overlapping analysis and identified 73 rare and 31 novel pathogenic variant candidates. Jin et al. (Jin et al. 2017) took another approach searching for de novo mutations through WES in 18 family trios with healthy parents and early-onset high myopia children. In addition to the novel pathogenic gene $B S G$, two known high myopia candidate genes (LEPREL1 and GRMO), three oculopathy-related genes (FAM161A, GLA, and CACNA1F), and a further possible gene (MAOA) were also identified in this trio study.

The high prevalence of high myopia in East Asian population (Holden et al. 2016; Wu et al. 2015) and previous WES studies suggested the complex genetic mechanisms behind the disease despite its strong heritability in families. In this study, we applied a novel phenotype driven variant filtering approach on the WES data of 20 patients with familial high myopia to search for potential causal mutations. We also explored the functions of the candidate genes through gene expression profiling, network and pathway enrichment analysis.

\section{Materials \& Methods}

\section{Human Subjects}

This study included a total of 20 samples from 19 families (9 males and 11 females) of Han Chinese ancestry with non-syndromic familial high myopia. The human subjects were recruited at the ophthalmic clinic at Sichuan Academy of Medical Sciences \& Sichuan Provincial People's Hospital, Chengdu, China. Approval for the study was provided by the Institutional Review Boards of Sichuan Provincial People's Hospital. Written informed consent forms were signed by all patients before the collection of peripheral blood and clinical data. The refractive errors of all patients were greater than $-6.00 \mathrm{D}$, as diagnosed by a team of high myopia specialists.

\section{Exome sequencing and variant calling}


90 Genomic DNA was isolated from peripheral blood samples of patients by using Genomic DNA

91 Extraction Kit (Invitrogen). The sequencing libraries were prepared and captured using 92 SureSelect Human All Exon V6 kit (Agilent Technologies) following the manufacturer's 93 instructions. Paired-end $(2 \times 150 \mathrm{bp})$ NGS was performed using HiSeq X-10 (Illumina, San Diego, 94 CA) according to the manufacturer's protocol.

95 Raw sequencing reads were filtered using the Trimmomatic program 96 (http://www.usadellab.org/cms/index.php?page=trimmomatic) to remove reads with low 97 sequencing quality at both ends. The cleaned reads were mapped to human reference genome 98 (GRCH37) by the BWA-MEM software (Li \& Durbin 2009), and PCR duplications were consensus call method to reach a good balance of high sensitivity and low false positive rate. Only variants detected by at least 2 methods out of 4 haplotype-based calling algorithms (Platypus, samtools, freebayes, and GATK haplotype caller) were kept in the final variant file. Variant annotation including gene functional consequence (gene context, amino acid change, splicing effect etc.), pathogenicity predictions by multiple computational methods (SIFT, Polyphen2, MutationTaster, CADD etc.), as well as healthy population allele frequencies from 1000G (Sudmant et al. 2015), ExAC (http://exac.broadinstitute.org/), and ESP (http://evs.gs.washington.edu/) database (Lek et al. 2016) were performed using the VEP software (McLaren et al. 2016).

\section{Variant filtering}

To help narrowing down the potential candidate variants for high myopia, we took a phenotype driven strategy focusing on rare variants in ocular diseases and high myopia phenotype related genes as illustrated in Fig. 1. First, we used a maximum allele frequency of 0.005 in any of the 3 public population databases: 1000G (http://browser.1000genomes.org/index.html), ExAC, and ESP dataset to filter out common variants. Then, only variants with high functional impact (Loss-of-function, or computationally predicted pathogenic missense variants) were considered. Pathogenicity of missense mutations was assumed if predicted pathogenic by at least 6 out of 8 computational methods (SIFT, PolyPhen2, LRT, MutatationTaster, MutationAssessor, FATHMM, CADD, DANN). Lastly, we focused on phenotype relevant genes. We considered only genes meeting both of the following 2 criteria. Firstly, Genes must be associated with eyerelated diseases. The ocular disease genes were assembled from the following 3 databases: genes associated with the myopia phenotype term (HP:0000545) in Human Phenotype Ontology (HPO: http://human-phenotype-ontology.github.io), or ocular disease genes from RetNet database (http://www.sph.uth.tmc.edu/retnet/) and OMIM (https://www.omim.org/). Secondly, genes must be known high myopia genes from previous publications (Aldahmesh et al. 2013; Chen et al. 2013; Jiang et al. 2014; Jin et al. 2017; Kloss et al. 2017; Shi et al. 2011; Sun et al. 2015; TranViet et al. 2013) (Complete gene list of known genes and ocular disease genes in Table S2) or within the myopia-associated (MYP) QTL regions (Table S1). Because all patients don't have any syndromic severe ocular diseases, a few variants in genes causing dominant OMIM ocular diseases not satisfying clinical phenotypes were excluded. 


\section{Functional enrichment and network analysis}

We chose a recent RNA-seq expression profile GSE94437 and a gene microarray expression profile GSE41102 to explore the expression pattern of the compiled complete list of ocular disease genes. For the GSE94437, RPKM was transform by $\log _{2}(\mathrm{RPKM}+0.001)$. To test the expression differences of the 709 ocular disease genes versus other genes, onesided t-test was applied to obtain the statistical significance. The Gene Ontology (GO) is a hierarchically organized, controlled vocabulary to consistently describe and annotate gene products (Ashburner et al. 2000). Joint terms may give insight on the shared biological processes, and enrichment analysis can make use of term-term relationships (Huang da et al. 2009; Kuleshov et al. 2016). The ReactomeFIViz app (Wu et al. 2014) was designed to find GO, pathways and network patterns. Thus we used ReactomeFIViz app and Cytoscape 3.5.1 to perform GO enrichment analysis of candidate genes. Using all the protein-coding genes in the genome as background, we carried out the GO enrichment for both the 12 candidate gene set and the 709 eye disease gene set. ReactomeFIViz was also used to explore the network features of candidate genes in the manually curated pathway-based protein functional interaction (FI) network covering over $60 \%$ of human proteins (Wu et al. 2010).

\section{Results}

In this study, WES from 20 patients with high myopia were performed to find disease-associated mutations, followed by pathway, GO enrichment and network analysis (Materials \& Methods). From WES, we generated an average of $10.7 \mathrm{~Gb}$ of sequence with $121 \times$ mean target coverage for each individual as paired-end, 150-bp reads. All samples had more than $95 \%$ of target bases covered by at least 10 reads. There are an average of 49904 SNPs and small indels called per sample. After multiple steps of variant filtering considering MAF, functional impact, phenotype associations and QTL overlapping information, a total of 20 potential pathogenic ( 3 splicing, 1 frame-shift and 16 deleterious missense) heterozygous variants in 12 genes were identified in 16 patients (Table 1).

There were 8 pathogenic variants identified from 5 known high myopia genes, including ADAMTS18, CSMD1, P3H2, RPGR and SLC39A5. Patient R0020 had a clear molecular diagnosis with one missense variant rs756666376 in gene SLC39A5 (MYP24, autosomal dominant inheritance). Rs756666376 (p.Gly293Arg) is extremely rare in healthy population, absent in $1000 \mathrm{G}$ data, with only one heterozygote in 4325 East Asians (MAF=0.00012) and two heterozygotes in 33359 Non-Finnish Europeans $(\mathrm{MAF}=0.00003)$ in ExAC database. The SNP is highly conserved and predicted to be deleterious by all of the eight computational methods in our variant annotation. The $R P G R$ gene is located on the $\mathrm{Xp} 21.1$ and plays a role in ciliogenesis and photoreceptor integrity. In gene $R P G R$, sample R0015 had a heterozygous loss-of-function mutation in the second intron $(\mathrm{c} .154+4 \mathrm{~A}>\mathrm{G})$ potentially affecting splicing as predicted by the 
167

168

169

170

171

172

173

174

175

176

177

178

179

180

181

182

183

184

185

186

187

188

189

190

191

192

193

194

195

196

197

198

199

200

201

202

203

204

205

206

207

adaptive boosting method in the splicing consensus region (Jian et al. 2014) and sample R0016 had a rare heterozygous pathogenic missense mutation (rs774982456, c.1832A $>\mathrm{G}$ ). Other than the known high myopia genes, we also discovered 12 rare potentially pathogenic heterozygous variants located in other MYP QTL regions, suggesting potential new candidate genes explaining these QTLs. Among these ocular disease related or direct high myopia related genes, 5 genes (CSMD1, HSPG2, RPGR, SEMA4A and USH2A) have pathogenic variants in multiple patients.

To look deep into the genes with pathogenic variants associated with high myopia, we assembled a list of 709 genes associated with eye diseases (details in variant filtering section of Materials \& Methods), including 58 known high myopia genes and 651 ocular disease genes (Table S2). Clinical phenotype related studies have shown that retinal, choroidal and scleral lesions are highfrequency phenotypes in high myopia patients (Brussee et al. 2014; Gupta et al. 2015; Gupta et al. 2017). It would be natural to assume that myopia related genes would be highly expressed in retina and sclera tissues. To test this hypothesis, we first explored the expression pattern of all the 709 eye disease genes. The results showed that in the RNA-seq dataset, the expression of 709 genes was significantly higher than that of other genes in retina, retinal pigment epithelium (RPE), choroid and sclera $(\mathrm{p}<0.001$, Fig. S1). All candidate genes in our own high myopia cohort were located in the positive expression class when using the 709 eye disease genes as background (Fig. 2A). Looking further into the candidate gene expression differences among the three tissues, we found that 5 genes (PCDH15, CEP290, SLC39A5, CSMD1 and USH2A) have much higher expression in retinas (macular retina and peripheral retina), while $A B C A 4, S A G$, $R P G R$, and $S E M A 4 A$ are highly expressed in both sclera and retina (Fig. 2B). Microarray dataset confirmed the higher expression in retina for genes $P C D H 15$ and USH2A (Fig. 2C).

GO term enrichment was carried out for a comprehensive functional analysis of the 12 genes found in this study. Because our bioinformatics pipeline has a filtering step to include only eye disease related genes, which could lead to potential bias in the enrichment signal. Thus we did two GO enrichment analyses using either our 12 genes, or the 709 eye disease genes (complete list of enriched GO terms from both analyses are in table S3). Other than the enriched GO terms like visual perception, photoreceptor cell maintenance, retinoid metabolic process shared with the 709 genes, significant enrichment was uniquely observed in our candidate genes in eye pigment precursor transporter activity, opsin binding, zinc ion transmembrane related processes, microtubule binding et al. (Fig. 3). Interestingly, the visual phototransduction pathway was enriched by pathway analysis. Visual phototransduction is the photochemical reaction that takes place when light is converted to an electric signal in the retina (Smith et al. 2016). It's not surprising the malfunction of genes in this pathway will potentially lead to myopia. This pathway was also found highly enriched in differentially expressed genes during myopia development in a mouse study (Metlapally et al. 2016), which corroborated these genes' potential causal roles in high myopia.

We also explored the network characteristics in a FI network (Wu et al. 2010). Focused on the 12 genes from our own cohort, except for the direct interaction between RPGR and CEP290, other genes are scattered, but all genes can be linked to form a large network by some linker genes, 
208

209

210

211

212

213

214

215

216

217

218

219

220

221

222

223

224

225

226

227

228

229

230

231

232

233

234

235

236

237

238

239

240

241

242

243

244

245

246

247

such as EP300, CTNNB1 (Fig. 4). A network clustering algorithm (Newman 2006) divided this network into 4 network modules. The principal biological process of each module was eye development, retinoid metabolic process, visual perception and photoreceptor cell maintenance, respectively. There were some differences between modules in biological processes, but they were all related to vision. When using the 709 genes as background, only GO term photoreceptor cell cilium was found enriched in the modules (Figure S2). EP300 encodes protein p300, which is a transcriptional co-activator regulating hundreds of genes' transcription via chromatin remodeling, and is important in the processes of cell proliferation and differentiation. Mutations in EP300 are known to cause Rubinstein-Taybi syndrome (RTS). Interestingly, RTS patients with EP300 mutations were frequently documented with severe myopia phenotype (Bartholdi et al. 2007; Fergelot et al. 2016). Various visual defects (including familial exudative vitreoretinopathy, retina detachment and myopia etc.) have also been reported in recent WES studies of people with mutations in CTNNB1 (Li et al. 2017; Panagiotou et al. 2017).

\section{Discussion}

Whole genome sequencing and whole exome sequencing have now entered medical practice (Biesecker \& Green 2014). Whole genome sequencing is the most powerful method of disease gene identification, because this method targets both coding and regulatory non-coding variants, and can identify disease genes caused by SNVs, large indels, and other large structure variants as well. However, its cost is still daunting. Some previous studies have estimated that $\sim 85 \%$ of Mendelian disease mutations are located within the coding region, canonical splice acceptor and donor sites (Stenson et al. 2017). Thus the WES becomes the sweet spot rather than WGS (Teer \& Mullikin 2010). We used WES to identify causal gene mutations in 20 patients with high myopia. Potential pathogenic mutations were identified in 16 patients $(80.0 \%, 16 / 20)$. 20 mutations in 12 genes were potentially pathogenic variants for high myopia. Compared to the discovery rate in previous studies (Chen et al. 2013; Kloss et al. 2017; Sun et al. 2015), our phenotype driven filtering method yielded higher diagnostic rate.

In our study, SEMA4A, RPGR and HSPG2 each had 2 pathogenic mutations detected in our probands. Gene SEMA4A encodes a member of the semaphorin family of soluble and transmembrane proteins. This gene maps to chromosome $1 \mathrm{p} 36$, which is located within the MYP14 locus (Abid et al. 2006; Wojciechowski et al. 2006). Mutation in codon 345 from $\mathrm{G}$ to $\mathrm{C}$ and in codon 350 from $\mathrm{T}$ to $\mathrm{G}$ in exon 10 of the $S E M A 4 A$ gene resulted in an asp345-to-his (D345H) and a phe350-to-cys (F350C) substitution, respectively. A link between those two mutations and retinitis pigmentosa and retinal degeneration has been demonstrated (Abid et al. 2006; Berger et al. 2010). Retinitis pigmentosa GTPase regulator (RPGR) is one of the main genes causing X-linked retinitis pigmentosa (XLRP). It was suggested that over $70 \%$ of XLRP cases were caused by RPGR mutations (Breuer et al. 2002; Sharon et al. 2003). Multiple studies have shown that female heterozygous $R P G R$ mutation carriers had early-onset high myopia in one of two eyes, especially those with protein truncating variants(Jin et al. 2006; Yokoyama et al. 2001). Some families showed even full penetrance of high myopia in heterozygous carriers 
248 (Parmeggiani et al. 2016). Both patients with a RPGR mutation are female carriers in our study.

249

250

251

252

253

254

255

256

257

258

259

260

261

262

263

264

265

266

267

268

269

270

271

272

273

274

275

276

277

278

279

280

281

282

283

284

285

286

287

288
The incomplete penetrance of XLRP phenotype of other RPGR carriers suggested that annual follow up examinations checking symptoms of RP is warranted. Gene HSPG2 encodes a protein called perlecan (Farach-Carson \& Carson 2007; Warren et al. 2015). Perlecan is a heparan sulfate proteoglycan, which interacts with many other proteins and has a variety of functions, such that mutation of the gene has pleiotropic effects. Schwartz-Jampel syndrome (SJS) is a rare autosomal recessive skeletal dysplasia with myotonia, short stature, and low-set ears and myopia (Kubrey et al. 2015). The two damaging missense mutations (c.12238G $>$ A and c.1940G $>A$ ) in HSPG 2 each occured in one patient. In our current cohort, 4 heterozygote variants in gene $U S H 2 A$ were identified, which fall within QTL MYP14. USH2A is a large gene with 73 exons and encodes at least 2 different isoforms. The mutations in the USH2A genes are responsible for $5 \sim 10 \%$ of the cases with retinitis pigmentosa and $60 \sim 90 \%$ of the cases with Usher syndrome type II (Baux et al. 2014; Pennings et al. 2004; Slijkerman et al. 2016).

Gene $A B C A 4$ is specifically expressed in cone and rod photoreceptor outer segments (Molday et al. 2000). The ABCA4 protein is active following phototransduction. $A B C A 4$ mutations can result in multiple vision related phenotypes (Cideciyan et al. 2009; Klevering et al. 2004; Shroyer et al. 1999; Valverde et al. 2007) including Retinitis pigmentosa, Fundus flavimaculatus, Cone-rod dystrophy, and Stargardt disease (Lin et al. 2016), which is characterized by juvenile macular degeneration. In addition, a missense variant c. $1268 \mathrm{~A}>\mathrm{G}$ in $A B C A 4$ was recently found to be responsible for myopia (D'Angelo et al. 2017). A novel missense rare variant (not observed in $1000 \mathrm{G}$, ESP, or ExAC database) c.4553G>A (p.Ser1518Asn) was found in our patient R0025. Yzer et al. (Yzer et al. 2012) made a mutation analysis for gene CEP290 and found that patients with a different mutation c.5587-1G $>$ C showed myopia. Based on linkage and haplotype analysis, Sudha et al. (Nallasamy et al. 2007) identified a presumptive myopia locus in gene PCDH15. A novel frameshift mutation (c.1081_1082delGA) was found in one patient R0018. These functional evidences suggested that carriers of high impact variants in these severe recessive inheritance ocular disease genes might be at higher risk for high myopia. When we relaxed the computational prediction filtering criteria for missense variants to at least 5 or 4 out of 8 methods, we obtained 1 or 2 extra candidate variants (Table S4). This suggested that our pipeline is relatively robust to the computational prediction cut-offs. Despite published evidences of the connections with myopia for the genes found in our cohort, none of the candidate variants were found in previous published sequencing studies of myopia (Aldahmesh et al. 2013; Chen et al. 2013; Jiang et al. 2014; Jin et al. 2017; Kloss et al. 2017; Shi et al. 2011; Sun et al. 2015; Tran-Viet et al. 2013), which highlighted the strong heterogeneity even in familial high myopia. The molecular functional impact of these mutations on the penetrance and severity of various ocular disease phenotypes would need further functional studies.

There are some limitations to our current study due to the small sample size and availability of family genetic data. Although our phenotype driven analysis approach has boosted the probabilities of the final variants associated with high myopia, the statistical significance of any genuine associated genes would need large sample size gene-level burden test (Lee et al. 2014). Alternatively, extra genetic validation of the causal relationship of these variants with high 
289

290

291

292

293

294

295

296

297

298

299

300

301

302

303

304

305

306

307

308

309

310

\section{1}

312

313

314

315

316

317

myopia would require family segregation analysis with extended family phenotyping and genotyping. In our study, R0027 (daughter) and R0029 (father) are the only 2 samples from the same family. After our bioinformatics filtering process, there are 2 candidate variants left in both patients and both variants are shared and consistent with Mendelian inheritance. One is the heterozygote c.3826G $>$ A SNP in CSMD1 listed in Table 1, the other is a missense variant c. $2338 \mathrm{C}>\mathrm{G}$ (p.Pro780Ala) in COL4A5 on chromosome $\mathrm{X}$ with the daughter's genotype being a heterozygote and the father's genotype being a hemizygote. Deletions or pathogenic missense variants in COL4A5 are known to cause X-linked dominant Alport syndrome (Knebelmann et al. 1996), however, neither patient exhibits the clinical phenotypes of Alport syndrome. Therefore, this $C O L 4 A 5$ variant was excluded from our final candidate list.

\section{Conclusions}

There is a large proportion of genetic heritability of high myopia still unexplained by known myopia genes. WES enables thorough and unbiased genetic analysis of candidate genes as well as novel gene discoveries. In this study, we took a novel bioinformatics screening approach combining ocular disease gene annotation, myopia phenotype to gene association, and rare variant functional effect filtering narrowing down potential causal variants. Systematic mutation analysis of high myopia genes was further analyzed by FI network, GO and pathway enrichment, which expanded our current understanding of high myopia. These variants, especially those on novel high myopia genes, expanded the mutation spectrum of myopia genes and provided clues for further genetic screening targets.

\section{Acknowledgements}

We would like to thank all the patients for participating in this study and Dr. Yongcheng Dong and Xin Ma for feedbacks on Bioinformatics analysis. L.W. is supported by Specialized Research Fund for the Doctoral Program of Higher Education (Grant No. 20130181110079). B.D., Z.W., and X.M. are supported by the National Major Scientific Equipment program (Grant No. 2012YQ12008005). 


\section{References}

319

320

321

322

323

324

325

326

327

328

329

330

331

332

333

334

335

336

337

338

339

340

341

342

343

344

345

346

347

348

349

350

351

352

353

354

355

356

357

Abid A, Ismail M, Mehdi SQ, and Khaliq S. 2006. Identification of novel mutations in the SEMA4A gene associated with retinal degenerative diseases. J Med Genet 43:378-381. 10.1136/jmg.2005.035055

Aldahmesh MA, Khan AO, Alkuraya H, Adly N, Anazi S, Al-Saleh AA, Mohamed JY, Hijazi H, Prabakaran S, Tacke M, Al-Khrashi A, Hashem M, Reinheckel T, Assiri A, and Alkuraya FS. 2013. Mutations in LRPAP1 are associated with severe myopia in humans. Am J Hum Genet 93:313-320. 10.1016/j.ajhg.2013.06.002

Andrew T, Maniatis N, Carbonaro F, Liew SH, Lau W, Spector TD, and Hammond CJ. 2008. Identification and replication of three novel myopia common susceptibility gene loci on chromosome 3q26 using linkage and linkage disequilibrium mapping. PLoS Genet 4:e1000220. 10.1371/journal.pgen.1000220

Ashburner M, Ball CA, Blake JA, Botstein D, Butler H, Cherry JM, Davis AP, Dolinski K, Dwight SS, Eppig JT, Harris MA, Hill DP, Issel-Tarver L, Kasarskis A, Lewis S, Matese JC, Richardson JE, Ringwald M, Rubin GM, and Sherlock G. 2000. Gene ontology: tool for the unification of biology. The Gene Ontology Consortium. Nat Genet 25:25-29. 10.1038/75556

Bartholdi D, Roelfsema JH, Papadia F, Breuning MH, Niedrist D, Hennekam RC, Schinzel A, and Peters DJM. 2007. Genetic heterogeneity in Rubinstein-Taybi syndrome: delineation of the phenotype of the first patients carrying mutations in EP300. J Med Genet 44:327-333. 10.1136/jmg.2006.046698

Baux D, Blanchet C, Hamel C, Meunier I, Larrieu L, Faugere V, Vache C, Castorina P, Puech B, Bonneau D, Malcolm S, Claustres M, and Roux AF. 2014. Enrichment of LOVD-USHbases with 152 USH2A genotypes defines an extensive mutational spectrum and highlights missense hotspots. Hum Mutat 35:1179-1186. 10.1002/humu.22608

Berger W, Kloeckener-Gruissem B, and Neidhardt J. 2010. The molecular basis of human retinal and vitreoretinal diseases. Prog Retin Eye Res 29:335-375. 10.1016/j.preteyeres.2010.03.004

Biesecker LG, and Green RC. 2014. Diagnostic clinical genome and exome sequencing. N Engl J Med 370:2418-2425. 10.1056/NEJMra1312543

Breuer DK, Yashar BM, Filippova E, Hiriyanna S, Lyons RH, Mears AJ, Asaye B, Acar C, Vervoort R, Wright AF, Musarella MA, Wheeler P, MacDonald I, lannaccone A, Birch D, Hoffman DR, Fishman GA, Heckenlively JR, Jacobson SG, Sieving PA, and Swaroop A. 2002. A comprehensive mutation analysis of RP2 and RPGR in a North American cohort of families with X-linked retinitis pigmentosa. Am J Hum Genet 70:1545-1554. 10.1086/340848

Brussee C, Buitendijk GHS, Springelkamp H, Snabel M, Luyten GPM, Van Rijn GA, Boon CJF, Geerards A, Verhoeven VJM, and Klaver CCW. 2014. Frequency of retinal pathology in high myopia. The MYST study. Investigative Ophthalmology \& Visual Science 55:3617-3617\%@ 1552-5783.

Chen Y, Zhang Q, Shen T, Xiao X, Li S, Guan L, Zhang J, Zhu Z, Yin Y, Wang P, Guo X, Wang J, and Zhang Q. 2013. Comprehensive mutation analysis by whole-exome sequencing in 41 Chinese families with Leber congenital amaurosis. Invest Ophthalmol Vis Sci 54:4351-4357. 10.1167/iovs.13-11606

Cideciyan AV, Swider M, Aleman TS, Tsybovsky Y, Schwartz SB, Windsor EA, Roman AJ, Sumaroka A, Steinberg JD, Jacobson SG, Stone EM, and Palczewski K. 2009. ABCA4 disease progression and a proposed strategy for gene therapy. Hum Mol Genet 18:931-941. 10.1093/hmg/ddn421

D'Angelo R, Donato L, Venza I, Scimone C, Aragona P, and Sidoti A. 2017. Possible protective role of the ABCA4 gene c.1268A $>\mathrm{G}$ missense variant in Stargardt disease and syndromic retinitis pigmentosa in a Sicilian

Peer] reviewing PDF | (2018:02:25008:1:0:NEW 17 Jul 2018) 
family: Preliminary data. Int J Mol Med 39:1011-1020. 10.3892/ijmm.2017.2917

Dirani M, Chamberlain M, Shekar SN, Islam AF, Garoufalis P, Chen CY, Guymer RH, and Baird PN. 2006. Heritability of refractive error and ocular biometrics: the Genes in Myopia (GEM) twin study. Invest Ophthalmol Vis Sci 47:4756-4761. 10.1167/iovs.06-0270

Farach-Carson MC, and Carson DD. 2007. Perlecan--a multifunctional extracellular proteoglycan scaffold. Glycobiology 17:897-905. 10.1093/glycob/cwm043

Fergelot P, Van Belzen M, Van Gils J, Afenjar A, Armour CM, Arveiler B, Beets L, Burglen L, Busa T, Collet M, Deforges J, de Vries BB, Dominguez Garrido E, Dorison N, Dupont J, Francannet C, Garcia-Minaur S, Gabau Vila E, Gebre-Medhin S, Gener Querol B, Genevieve D, Gerard M, Gervasini CG, Goldenberg A, Josifova D, Lachlan K, Maas S, Maranda B, Moilanen JS, Nordgren A, Parent P, Rankin J, Reardon W, Rio M, Roume J, Shaw A, Smigiel R, Sojo A, Solomon B, Stembalska A, Stumpel C, Suarez F, Terhal P, Thomas S, Touraine R, Verloes A, Vincent-Delorme C, Wincent J, Peters DJ, Bartsch O, Larizza L, Lacombe D, and Hennekam RC. 2016. Phenotype and genotype in 52 patients with Rubinstein-Taybi syndrome caused by EP300 mutations. Am J Med Genet A 170:3069-3082. 10.1002/ajmg.a.37940

Guo $\mathrm{H}$, Tong $\mathrm{P}$, Liu Y, Xia L, Wang T, Tian Q, Li Y, Hu Y, Zheng Y, Jin X, Li Y, Xiong W, Tang B, Feng Y, Li J, Pan Q, Hu Z, and Xia K. 2015. Mutations of P4HA2 encoding prolyl 4-hydroxylase 2 are associated with nonsyndromic high myopia. Genet Med 17:300-306. 10.1038/gim.2015.28

Gupta P, Saw SM, Cheung CY, Girard MJA, Mari JM, Bhargava M, Tan C, Tan M, Yang A, and Tey F. 2015. Choroidal thickness and high myopia: a case-control study of young Chinese men in Singapore. Acta ophthalmologica 93.

Gupta P, Thakku SG, Saw SM, Tan M, Lim E, Tan M, Cheung CMG, Wong TY, and Cheng CY. 2017. Characterization of Choroidal Morphologic and Vascular Features in Young Men With High Myopia Using Spectral-Domain Optical Coherence Tomography. Am J Ophthalmol 177:27-33. 10.1016/j.ajo.2017.02.001

Hammond CJ, Snieder H, Gilbert CE, and Spector TD. 2001. Genes and environment in refractive error: the twin eye study. Invest Ophthalmol Vis Sci 42:1232-1236.

Holden BA, Fricke TR, Wilson DA, Jong M, Naidoo KS, Sankaridurg P, Wong TY, Naduvilath TJ, and Resnikoff S. 2016. Global Prevalence of Myopia and High Myopia and Temporal Trends from 2000 through 2050. Ophthalmology 123:1036-1042. 10.1016/j.ophtha.2016.01.006

Huang da W, Sherman BT, and Lempicki RA. 2009. Bioinformatics enrichment tools: paths toward the comprehensive functional analysis of large gene lists. Nucleic Acids Res 37:1-13. 10.1093/nar/gkn923

Jian X, Boerwinkle E, and Liu X. 2014. In silico prediction of splice-altering single nucleotide variants in the human genome. Nucleic Acids Res 42:13534-13544. 10.1093/nar/gku1206

Jiang D, Li J, Xiao X, Li S, Jia X, Sun W, Guo X, and Zhang Q. 2014. Detection of mutations in LRPAP1, CTSH, LEPREL1, ZNF644, SLC39A5, and SCO2 in 298 families with early-onset high myopia by exome sequencing. Invest Ophthalmol Vis Sci 56:339-345. 10.1167/iovs.14-14850

Jin ZB, Liu XQ, Hayakawa M, Murakami A, and Nao-i N. 2006. Mutational analysis of RPGR and RP2 genes in Japanese patients with retinitis pigmentosa: identification of four mutations. Mol Vis 12:1167-1174.

Jin ZB, Wu J, Huang XF, Feng CY, Cai XB, Mao JY, Xiang L, Wu KC, Xiao X, Kloss BA, Li Z, Liu Z, Huang S, Shen M, Cheng FF, Cheng XW, Zheng ZL, Chen X, Zhuang W, Zhang Q, Young TL, Xie T, Lu F, and Qu J. 2017. Triobased exome sequencing arrests de novo mutations in early-onset high myopia. Proc Natl Acad Sci U S A 114:4219-4224. 10.1073/pnas.1615970114 
Katz J, Tielsch JM, and Sommer A. 1997. Prevalence and risk factors for refractive errors in an adult inner city population. Invest Ophthalmol Vis Sci 38:334-340.

Kempen JH, Mitchell P, Lee KE, Tielsch JM, Broman AT, Taylor HR, Ikram MK, Congdon NG, and O'Colmain BJ. 2004. The prevalence of refractive errors among adults in the United States, Western Europe, and Australia. Archives of ophthalmology (Chicago, III: 1960) 122:495-505\%@ 0003-9950.

Klevering BJ, Maugeri A, Wagner A, Go SL, Vink C, Cremers FP, and Hoyng CB. 2004. Three families displaying the combination of Stargardt's disease with cone-rod dystrophy or retinitis pigmentosa. Ophthalmology 111:546-553. 10.1016/j.ophtha.2003.06.010

Kloss BA, Tompson SW, Whisenhunt KN, Quow KL, Huang SJ, Pavelec DM, Rosenberg T, and Young TL. 2017. Exome Sequence Analysis of 14 Families With High Myopia. Invest Ophthalmol Vis Sci 58:1982-1990. 10.1167/iovs.16-20883

Knebelmann B, Breillat C, Forestier L, Arrondel C, Jacassier D, Giatras I, Drouot L, Deschenes G, Grunfeld JP, Broyer M, Gubler MC, and Antignac C. 1996. Spectrum of mutations in the COL4A5 collagen gene in X-linked Alport syndrome. Am J Hum Genet 59:1221-1232.

Kubrey S, Solanki D, and Agrawal S. 2015. Schwartz-Jampel Syndrome (SJS) a rare entity: case report. JOURNAL OF EVOLUTION OF MEDICAL AND DENTAL SCIENCES-JEMDS 4:7538-7546 \%@ 2278-4748.

Kuleshov MV, Jones MR, Rouillard AD, Fernandez NF, Duan $Q$, Wang Z, Koplev S, Jenkins SL, Jagodnik KM, Lachmann A, McDermott MG, Monteiro CD, Gundersen GW, and Ma'ayan A. 2016. Enrichr: a comprehensive gene set enrichment analysis web server 2016 update. Nucleic Acids Res 44:W90-97. 10.1093/nar/gkw377

Lee $\mathrm{S}$, Abecasis GR, Boehnke M, and Lin X. 2014. Rare-variant association analysis: study designs and statistical tests. Am J Hum Genet 95:5-23. 10.1016/j.ajhg.2014.06.009

Lek M, Karczewski KJ, Minikel EV, Samocha KE, Banks E, Fennell T, O'Donnell-Luria AH, Ware JS, Hill AJ, Cummings BB, Tukiainen T, Birnbaum DP, Kosmicki JA, Duncan LE, Estrada K, Zhao F, Zou J, Pierce-Hoffman E, Berghout J, Cooper DN, Deflaux N, DePristo M, Do R, Flannick J, Fromer M, Gauthier L, Goldstein J, Gupta N, Howrigan D, Kiezun A, Kurki MI, Moonshine AL, Natarajan P, Orozco L, Peloso GM, Poplin R, Rivas MA, Ruano-Rubio V, Rose SA, Ruderfer DM, Shakir K, Stenson PD, Stevens C, Thomas BP, Tiao G, Tusie-Luna MT, Weisburd B, Won HH, Yu D, Altshuler DM, Ardissino D, Boehnke M, Danesh J, Donnelly S, Elosua R, Florez JC, Gabriel SB, Getz G, Glatt SJ, Hultman CM, Kathiresan S, Laakso M, McCarroll S, McCarthy MI, McGovern D, McPherson R, Neale BM, Palotie A, Purcell SM, Saleheen D, Scharf JM, Sklar P, Sullivan PF, Tuomilehto J, Tsuang MT, Watkins HC, Wilson JG, Daly MJ, MacArthur DG, and Exome Aggregation C. 2016. Analysis of protein-coding genetic variation in 60,706 humans. Nature 536:285-291. 10.1038/nature19057

$\mathrm{Li} \mathrm{H}$, and Durbin R. 2009. Fast and accurate short read alignment with Burrows-Wheeler transform. Bioinformatics 25:1754-1760. 10.1093/bioinformatics/btp324

Li N, Xu Y, Li G, Yu T, Yao RE, Wang X, and Wang J. 2017. Exome sequencing identifies a de novo mutation of CTNNB1 gene in a patient mainly presented with retinal detachment, lens and vitreous opacities, microcephaly, and developmental delay: Case report and literature review. Medicine (Baltimore) 96:e6914. 10.1097/md.00000000000006914

Li YJ, Guggenheim JA, Bulusu A, Metlapally R, Abbott D, Malecaze F, Calvas P, Rosenberg T, Paget S, Creer RC, Kirov G, Owen MJ, Zhao B, White T, Mackey DA, and Young TL. 2009. An international collaborative familybased whole-genome linkage scan for high-grade myopia. Invest Ophthalmol Vis Sci 50:3116-3127. 


\subsection{7/iovs.08-2781}

Lin B, Cai XB, Zheng ZL, Huang XF, Liu XL, Qu J, and Jin ZB. 2016. Clinical and genetic analyses reveal novel pathogenic ABCA4 mutations in Stargardt disease families. Sci Rep 6:35414. 10.1038/srep35414

Lopes MC, Andrew T, Carbonaro F, Spector TD, and Hammond CJ. 2009. Estimating heritability and shared environmental effects for refractive error in twin and family studies. Invest Ophthalmol Vis Sci 50:126-131. 10.1167/iovs.08-2385

McLaren W, Gil L, Hunt SE, Riat HS, Ritchie GR, Thormann A, Flicek P, and Cunningham F. 2016. The Ensembl Variant Effect Predictor. Genome Biol 17:122. 10.1186/s13059-016-0974-4

Metlapally R, Park HN, Chakraborty R, Wang KK, Tan CC, Light JG, Pardue MT, and Wildsoet CF. 2016. GenomeWide Scleral Micro- and Messenger-RNA Regulation During Myopia Development in the Mouse. Invest Ophthalmol Vis Sci 57:6089-6097. 10.1167/iovs.16-19563

Molday LL, Rabin AR, and Molday RS. 2000. ABCR expression in foveal cone photoreceptors and its role in Stargardt macular dystrophy. Nat Genet 25:257-258. 10.1038/77004

Mordechai S, Gradstein L, Pasanen A, Ofir R, El Amour K, Levy J, Belfair N, Lifshitz T, Joshua S, Narkis G, Elbedour K, Myllyharju J, and Birk OS. 2011. High myopia caused by a mutation in LEPREL1, encoding prolyl 3hydroxylase 2. Am J Hum Genet 89:438-445. 10.1016/j.ajhg.2011.08.003

Morgan IG, Ohno-Matsui K, and Saw S-M. 2012. Myopia. The Lancet 379:1739-1748.

Nakanishi H, Yamada R, Gotoh N, Hayashi H, Yamashiro K, Shimada N, Ohno-Matsui K, Mochizuki M, Saito M, lida T, Matsuo K, Tajima K, Yoshimura N, and Matsuda F. 2009. A genome-wide association analysis identified a novel susceptible locus for pathological myopia at 11q24.1. PLoS Genet 5:e1000660. 10.1371/journal.pgen.1000660

Nallasamy S, Paluru PC, Devoto M, Wasserman NF, Zhou J, and Young TL. 2007. Genetic linkage study of high-grade myopia in a Hutterite population from South Dakota. Mol Vis 13:229-236.

Newman ME. 2006. Modularity and community structure in networks. Proc Natl Acad Sci U S A 103:8577-8582. 10.1073/pnas.0601602103

Ng SB, Turner EH, Robertson PD, Flygare SD, Bigham AW, Lee C, Shaffer T, Wong M, Bhattacharjee A, Eichler EE, Bamshad M, Nickerson DA, and Shendure J. 2009. Targeted capture and massively parallel sequencing of 12 human exomes. Nature 461:272-276. 10.1038/nature08250

Panagiotou ES, Sanjurjo Soriano C, Poulter JA, Lord EC, Dzulova D, Kondo H, Hiyoshi A, Chung BH, Chu YW, Lai CHY, Tafoya ME, Karjosukarso D, Collin RWJ, Topping J, Downey LM, Ali M, Inglehearn CF, and Toomes C. 2017. Defects in the Cell Signaling Mediator beta-Catenin Cause the Retinal Vascular Condition FEVR. Am J Hum Genet 100:960-968. 10.1016/j.ajhg.2017.05.001

Parmeggiani F, Barbaro V, De Nadai K, Lavezzo E, Toppo S, Chizzolini M, Palu G, Parolin C, and Di lorio E. 2016. Identification of novel X-linked gain-of-function RPGR-ORF15 mutation in Italian family with retinitis pigmentosa and pathologic myopia. Sci Rep 6:39179. 10.1038/srep39179

Pennings RJ, Te Brinke H, Weston MD, Claassen A, Orten DJ, Weekamp H, Van Aarem A, Huygen PL, Deutman AF, Hoefsloot LH, Cremers FP, Cremers CW, Kimberling WJ, and Kremer H. 2004. USH2A mutation analysis in 70 Dutch families with Usher syndrome type II. Hum Mutat 24:185. 10.1002/humu.9259

Saw SM, Gazzard G, Shih-Yen EC, and Chua WH. 2005. Myopia and associated pathological complications. Ophthalmic Physiol Opt 25:381-391. 10.1111/j.1475-1313.2005.00298.x

Schwartz M, Haim M, and Skarsholm D. 1990. X-linked myopia: Bornholm eye disease. Linkage to DNA markers on 
481

482

483

484

485

486

487

488

489

490

491

492

493

494

495

496

497

498

499

500

501

502

503

504

505

506

507

508

509

510

511

512

513

514

515

516

517

518

519

520

521

the distal part of Xq. Clin Genet 38:281-286.

Sharon D, Sandberg MA, Rabe VW, Stillberger M, Dryja TP, and Berson EL. 2003. RP2 and RPGR mutations and clinical correlations in patients with X-linked retinitis pigmentosa. Am J Hum Genet 73:1131-1146. 10.1086/379379

Shi Y, Li Y, Zhang D, Zhang H, Li Y, Lu F, Liu X, He F, Gong B, Cai L, Li R, Liao S, Ma S, Lin H, Cheng J, Zheng H, Shan Y, Chen B, Hu J, Jin X, Zhao P, Chen Y, Zhang Y, Lin Y, Li X, Fan Y, Yang H, Wang J, and Yang Z. 2011. Exome sequencing identifies ZNF644 mutations in high myopia. PLoS Genet 7:e1002084. 10.1371/journal.pgen.1002084

Shroyer NF, Lewis RA, Allikmets R, Singh N, Dean M, Leppert M, and Lupski JR. 1999. The rod photoreceptor ATPbinding cassette transporter gene, $A B C R$, and retinal disease: from monogenic to multifactorial. Vision Res 39:2537-2544.

Slijkerman RW, Vache C, Dona M, Garcia-Garcia G, Claustres M, Hetterschijt L, Peters TA, Hartel BP, Pennings RJ, Millan JM, Aller E, Garanto A, Collin RW, Kremer H, Roux AF, and Van Wijk E. 2016. Antisense Oligonucleotide-based Splice Correction for USH2A-associated Retinal Degeneration Caused by a Frequent Deep-intronic Mutation. Mol Ther Nucleic Acids 5:e381. 10.1038/mtna.2016.89

Smith RL, Sivaprasad S, and Chong V. 2016. Retinal Biochemistry, Physiology and Cell Biology. Dev Ophthalmol 55:18-27. 10.1159/000431118

Stenson PD, Mort M, Ball EV, Evans K, Hayden M, Heywood S, Hussain M, Phillips AD, and Cooper DN. 2017. The Human Gene Mutation Database: towards a comprehensive repository of inherited mutation data for medical research, genetic diagnosis and next-generation sequencing studies. Hum Genet 136:665-677. 10.1007/s00439-017-1779-6

Sudmant PH, Rausch T, Gardner EJ, Handsaker RE, Abyzov A, Huddleston J, Zhang Y, Ye K, Jun G, Fritz MH, Konkel MK, Malhotra A, Stutz AM, Shi X, Casale FP, Chen J, Hormozdiari F, Dayama G, Chen K, Malig M, Chaisson MJP, Walter K, Meiers S, Kashin S, Garrison E, Auton A, Lam HYK, Mu XJ, Alkan C, Antaki D, Bae T, Cerveira E, Chines P, Chong Z, Clarke L, Dal E, Ding L, Emery S, Fan X, Gujral M, Kahveci F, Kidd JM, Kong Y, Lameijer EW, McCarthy S, Flicek P, Gibbs RA, Marth G, Mason CE, Menelaou A, Muzny DM, Nelson BJ, Noor A, Parrish NF, Pendleton M, Quitadamo A, Raeder B, Schadt EE, Romanovitch M, Schlattl A, Sebra R, Shabalin AA, Untergasser A, Walker JA, Wang M, Yu F, Zhang C, Zhang J, Zheng-Bradley X, Zhou W, Zichner T, Sebat J, Batzer MA, McCarroll SA, Mills RE, Gerstein MB, Bashir A, Stegle O, Devine SE, Lee C, Eichler EE, and Korbel JO. 2015. An integrated map of structural variation in 2,504 human genomes. Nature 526:75-81. $10.1038 /$ nature15394

Sun W, Huang L, Xu Y, Xiao X, Li S, Jia X, Gao B, Wang P, Guo X, and Zhang Q. 2015. Exome Sequencing on 298 Probands With Early-Onset High Myopia: Approximately One-Fourth Show Potential Pathogenic Mutations in RetNet Genes. Invest Ophthalmol Vis Sci 56:8365-8372. 10.1167/iovs.15-17555

Teer JK, and Mullikin JC. 2010. Exome sequencing: the sweet spot before whole genomes. Human molecular genetics 19:R145-R151 \%@ 1460-2083.

Tran-Viet KN, Powell C, Barathi VA, Klemm T, Maurer-Stroh S, Limviphuvadh V, Soler V, Ho C, Yanovitch T, Schneider G, Li YJ, Nading E, Metlapally R, Saw SM, Goh L, Rozen S, and Young TL. 2013. Mutations in SCO2 are associated with autosomal-dominant high-grade myopia. Am J Hum Genet 92:820-826. 10.1016/j.ajhg.2013.04.005

Valverde D, Riveiro-Alvarez R, Aguirre-Lamban J, Baiget M, Carballo M, Antinolo G, Millan JM, Garcia Sandoval B, 
522

523

524

525

526

527

528

529

530

531

532

533

534

535

536

537

538

539

540

541

542

543

544

545

546

547

548

549

550

551

552

553

554

555

556 and Ayuso C. 2007. Spectrum of the ABCA4 gene mutations implicated in severe retinopathies in Spanish patients. Invest Ophthalmol Vis Sci 48:985-990. 10.1167/iovs.06-0307

Vitale S, Sperduto RD, and Ferris FL, 3rd. 2009. Increased prevalence of myopia in the United States between 19711972 and 1999-2004. Arch Ophthalmol 127:1632-1639. 10.1001/archophthalmol.2009.303

Warren CR, Kassir E, Spurlin J, Martinez J, Putnam NH, and Farach-Carson MC. 2015. Evolution of the perlecan/HSPG2 gene and its activation in regenerating Nematostella vectensis. PLoS One 10:e0124578. 10.1371/journal.pone.0124578

Wojciechowski R, Moy C, Ciner E, Ibay G, Reider L, Bailey-Wilson JE, and Stambolian D. 2006. Genomewide scan in Ashkenazi Jewish families demonstrates evidence of linkage of ocular refraction to a QTL on chromosome 1p36. Hum Genet 119:389-399. 10.1007/s00439-006-0153-x

Wu G, Dawson E, Duong A, Haw R, and Stein L. 2014. ReactomeFIViz: a Cytoscape app for pathway and networkbased data analysis. F1000Res 3:146. 10.12688/f1000research.4431.2

Wu G, Feng X, and Stein L. 2010. A human functional protein interaction network and its application to cancer data analysis. Genome Biol 11:R53. 10.1186/gb-2010-11-5-r53

Wu LJ, You QS, Duan JL, Luo YX, Liu LJ, Li X, Gao Q, Zhu HP, He Y, Xu L, Jonas JB, Wang W, and Guo XH. 2015. Prevalence and associated factors of myopia in high-school students in Beijing. PLoS One 10:e0120764. 10.1371/journal.pone.0120764

Xiao X, Li S, Jia X, Guo X, and Zhang Q. 2016. X-linked heterozygous mutations in ARR3 cause female-limited early onset high myopia. Mol Vis 22:1257-1266.

Xu L, Wang Y, Li Y, Wang Y, Cui T, Li J, and Jonas JB. 2006. Causes of blindness and visual impairment in urban and rural areas in Beijing: the Beijing Eye Study. Ophthalmology 113:1134 e1131-1111. 10.1016/j.ophtha.2006.01.035

Yokoyama A, Maruiwa F, Hayakawa M, Kanai A, Vervoort R, Wright AF, Yamada K, Niikawa N, and Naoi N. 2001. Three novel mutations of the RPGR gene exon ORF15 in three Japanese families with X-linked retinitis pigmentosa. Am J Med Genet 104:232-238.

Young TL, Ronan SM, Drahozal LA, Wildenberg SC, Alvear AB, Oetting WS, Atwood LD, Wilkin DJ, and King RA. 1998. Evidence that a locus for familial high myopia maps to chromosome 18p. The American Journal of Human Genetics 63:109-119\%@ 0002-9297.

Yzer S, Hollander Al, Lopez I, Pott JW, de Faber JT, Cremers FP, Koenekoop RK, and van den Born LI. 2012. Ocular and extra-ocular features of patients with Leber congenital amaurosis and mutations in CEP290. Mol Vis 18:412-425.

Zhang Q. 2015. Genetics of Refraction and Myopia. Prog Mol Biol Transl Sci 134:269-279. 10.1016/bs.pmbts.2015.05.007 


\section{Table $\mathbf{1}$ (on next page)}

Variants identified in patients with high myopia.

Chromosome position in accordance with GRCh37/hg19 assembly. The HM is abbreviation of the high myopia. 
Table 1. Variants identified in patients with high myopia. Chromosome position based on GRCh37/hg 19 assembly. HM stands for 2 high myopia.

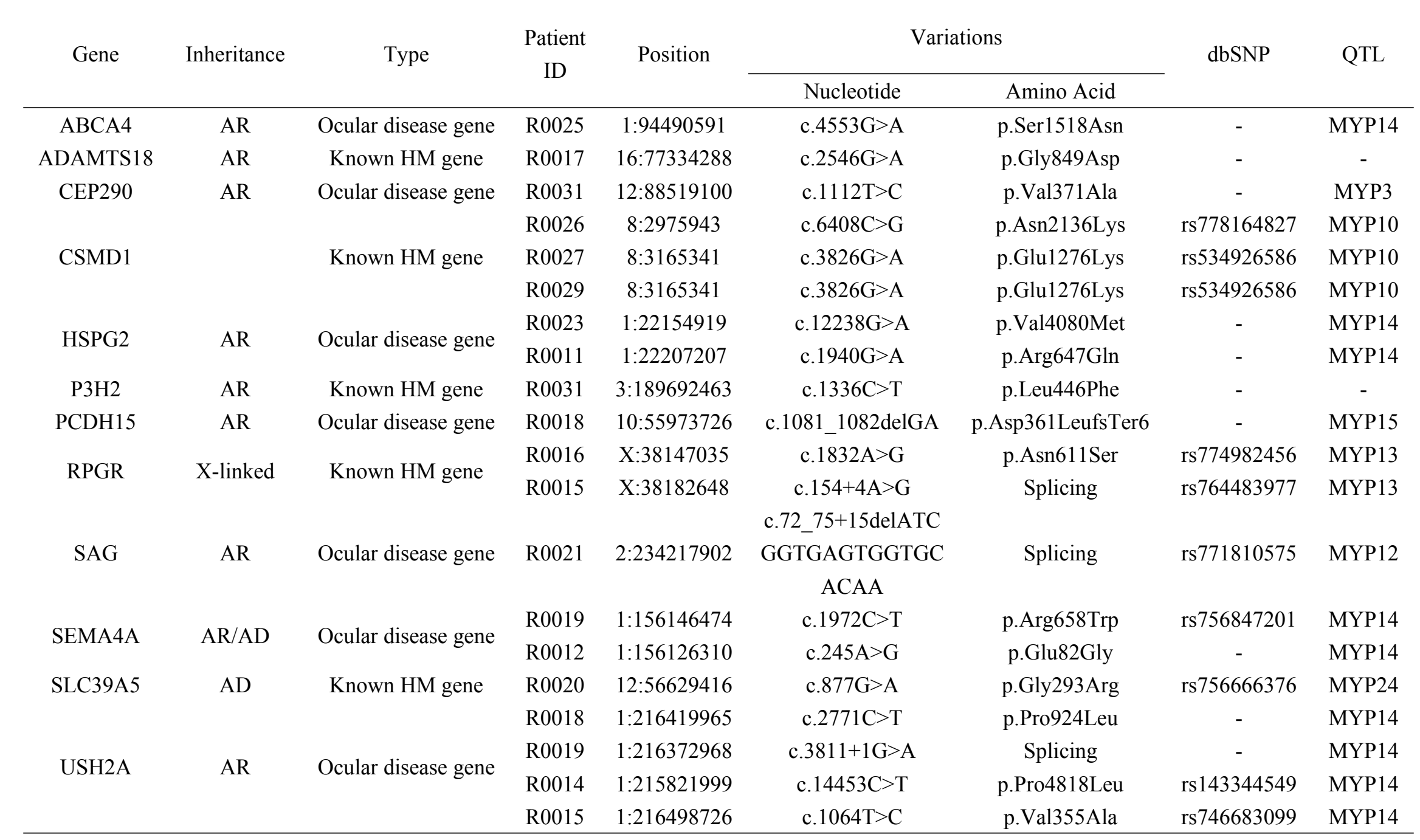


Figure 1

Overview of the variant filtering strategy and analysis of WES data.

We applied a phenotype driven strategy to filter the potential candidate variants for high myopia. Variant frequency in populations, mutation functional impact, and phenotype associations from RetNet, HPO, and OMIM are combined to narrow down the candidate variants.
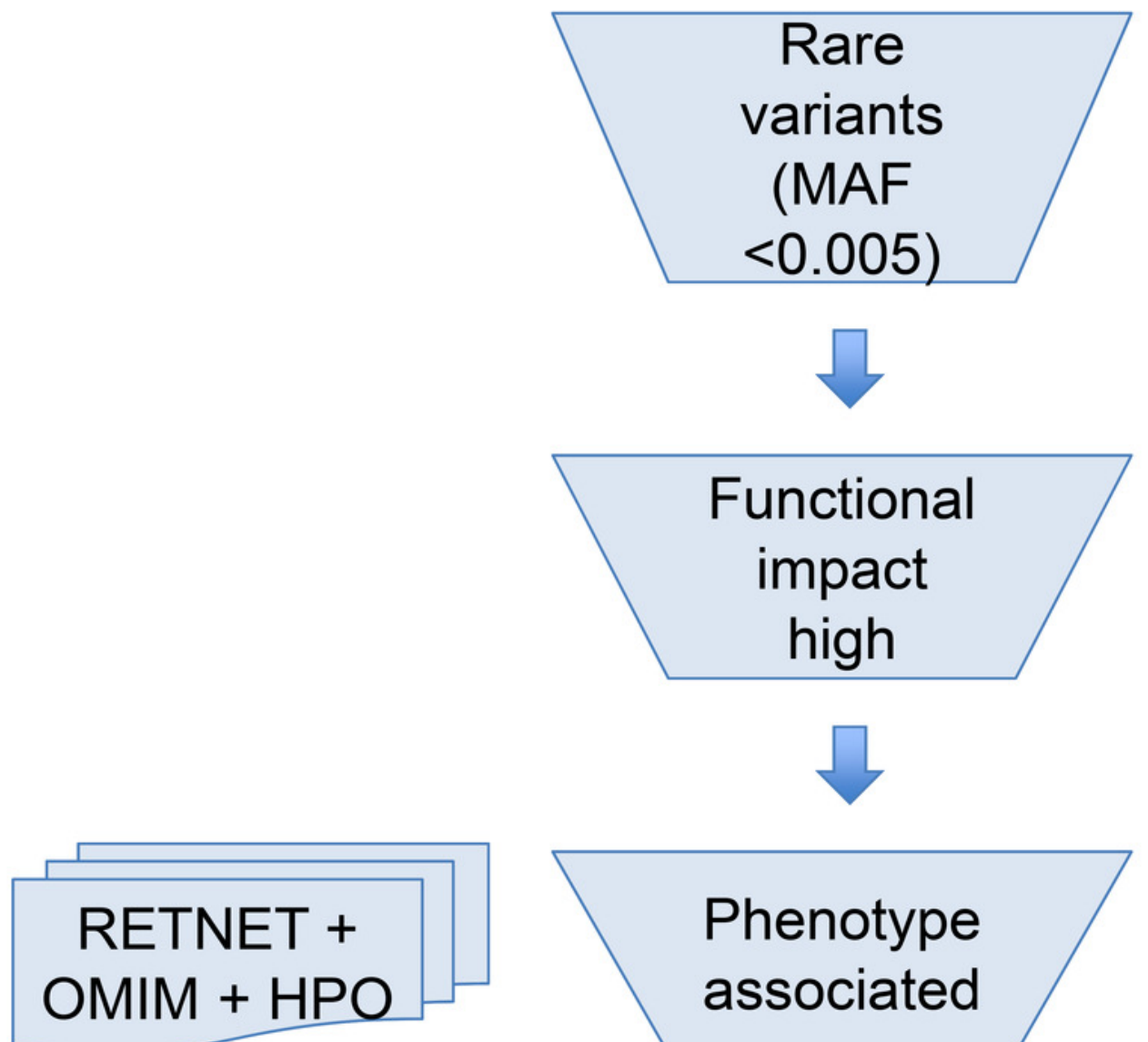
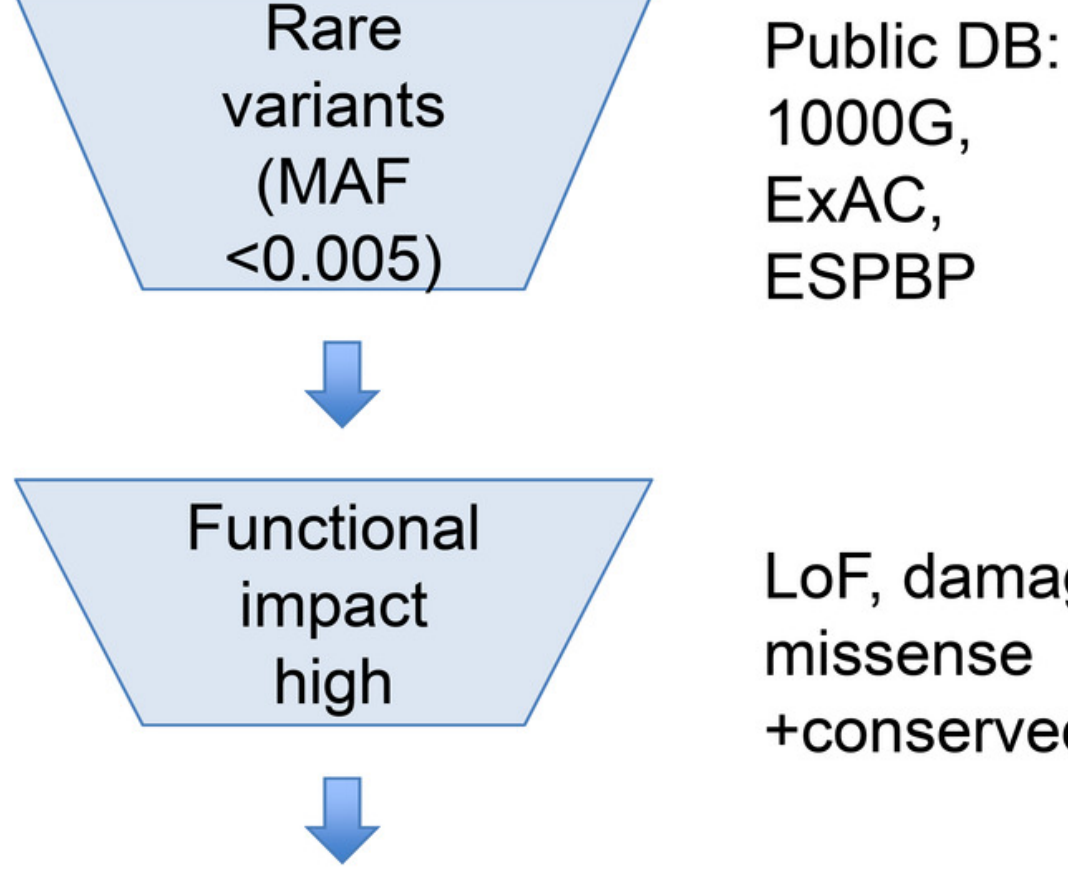
LoF, damaging missense +conserved
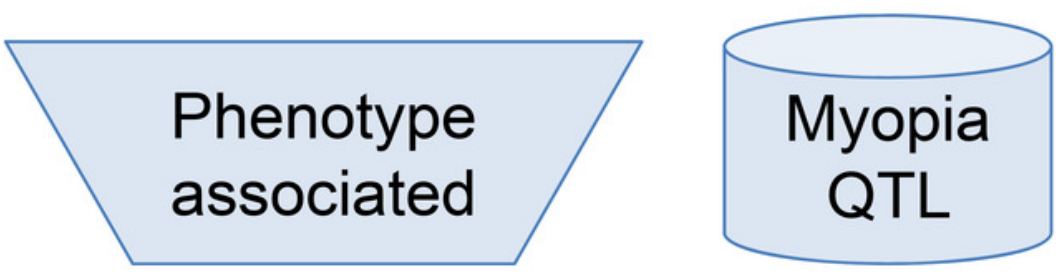

\section{Candidate Variants}




\section{Figure 2}

Hierarchical cluster analysis of gene expression.

(A) The heatmap of 709 known genes associated with eye diseases in RNA-seq expression profile. The 709 genes were divided into known high myopia genes and ocular disease genes, as shown in different colors in type column. Count column represents the sample count of pathogenic variants for our candidate genes. (B) The heatmap of candidate genes in RNA-seq expression profile. (C) The heatmap of candidate genes in microarray expression profile. 


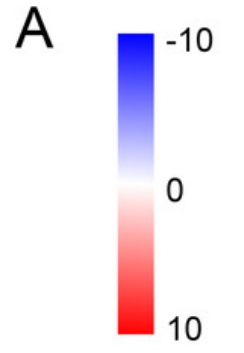

Type

Known gene

Ocular disease gene

Count

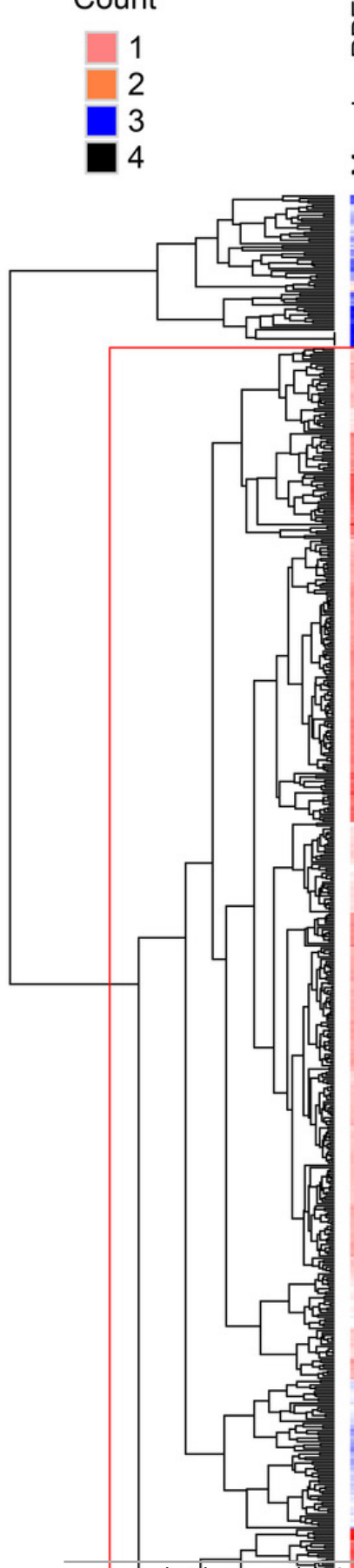

Peer reviening PDE

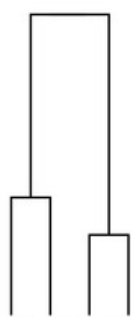

(1)

这 $\frac{0}{0}$

出,

음

은 응

О

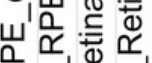

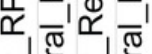

市 ब

응은 은은

$\sum \triangle \sum \propto$ Type Count
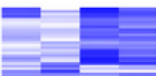

- $=$
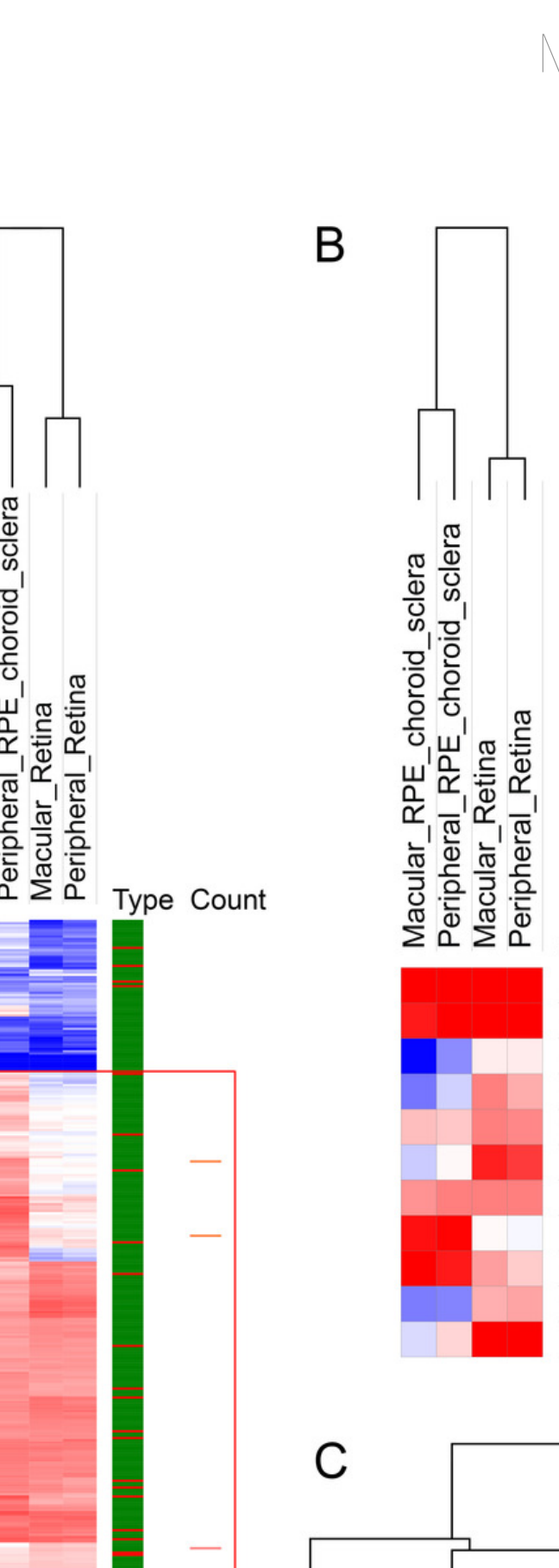

$-$
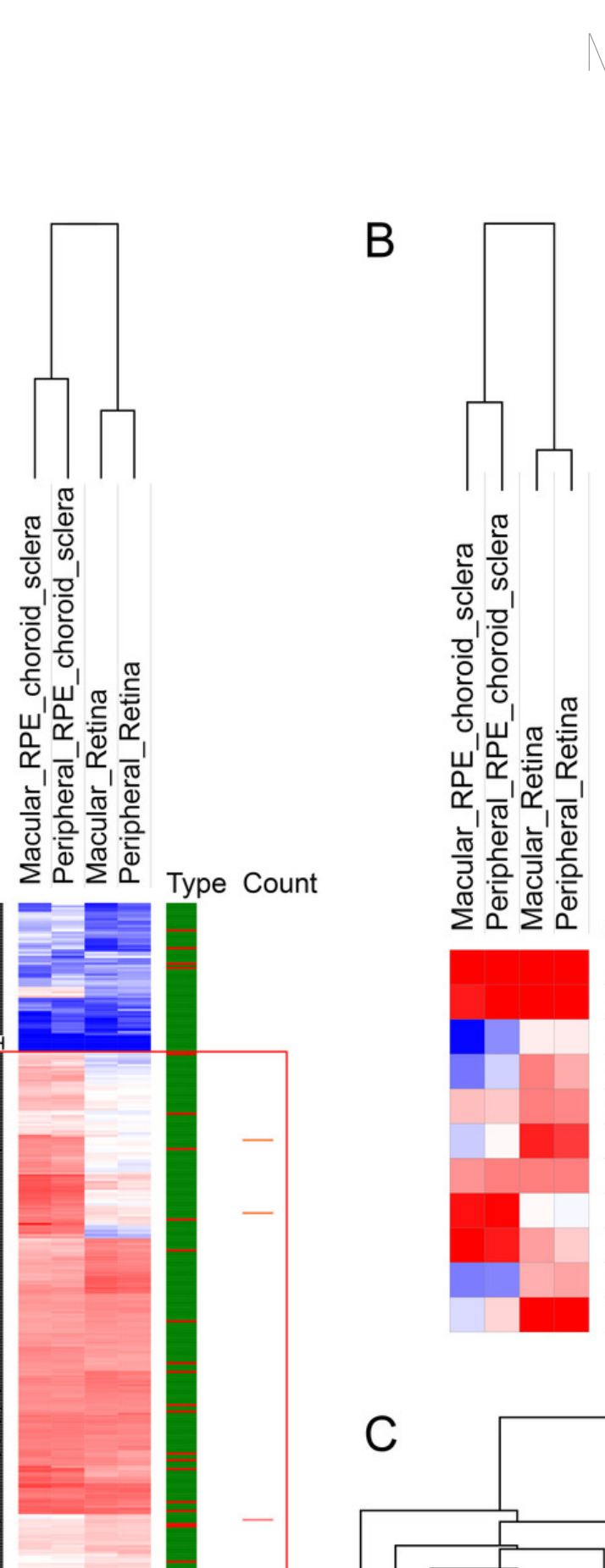
Figure 3

Top 10 significantly enriched GO terms only in candidate genes and not in the 709 eye disease genes.

(A) Molecular function. (B) Biological process. (C) Cellular component. X-axis is the $-\log _{10}(\mathrm{BH}$ adjusted P-value) from hypergeometric test of enrichment analysis. Complete list of enriched GO terms are listed in Table S3.

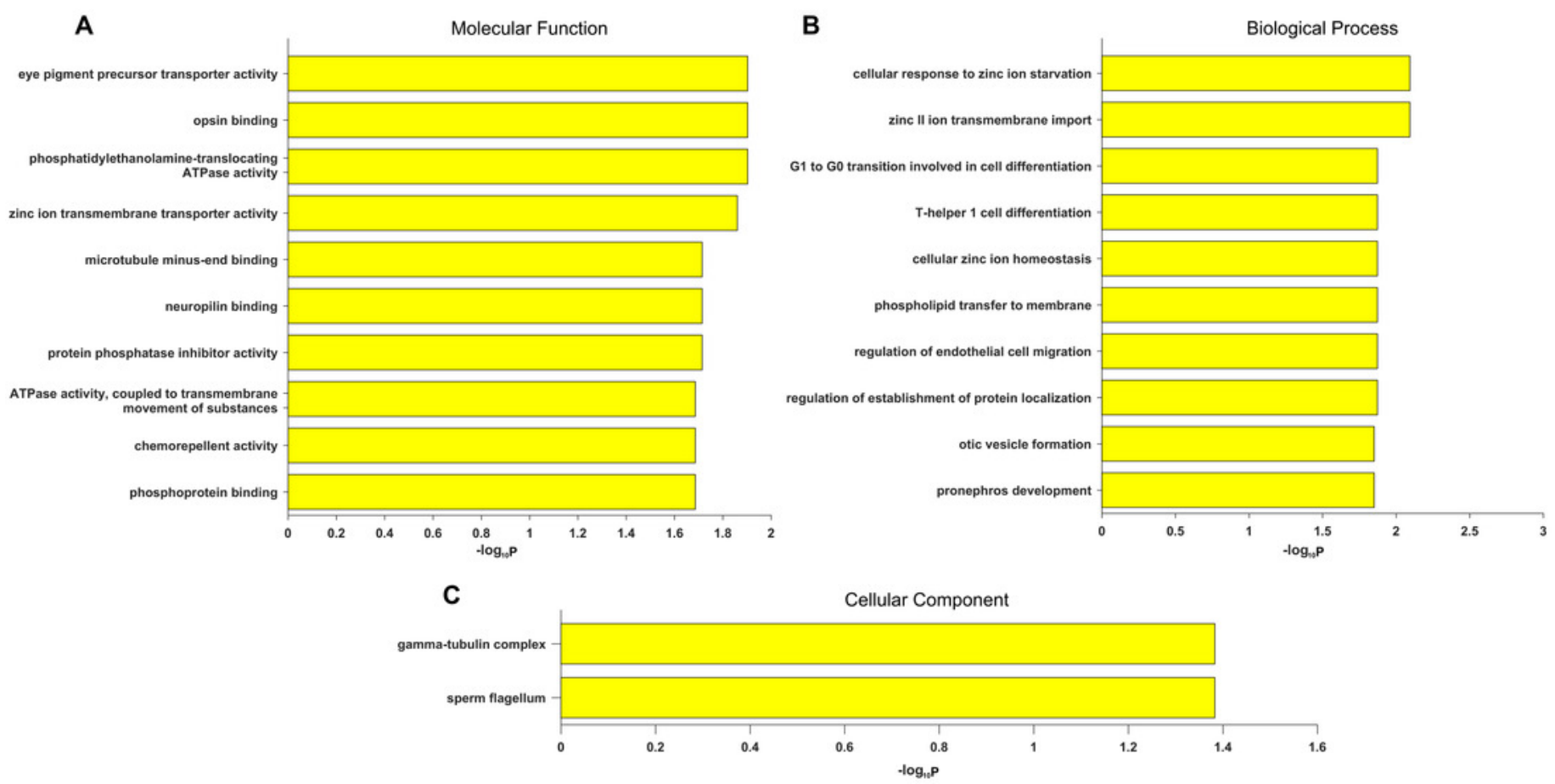




\section{Figure 4}

The network modules associated with high myopia candidate genes and linker genes in the functional interaction (FI) network.

This network can be divided into 4 network modules. The background colors of genes represent different modules. Principal biological process of each module was described. The candidate genes are black in text color, and the linker genes are red in text color. The circle size of each candidate gene is proportional to the number of samples with pathogenic variants for the gene.

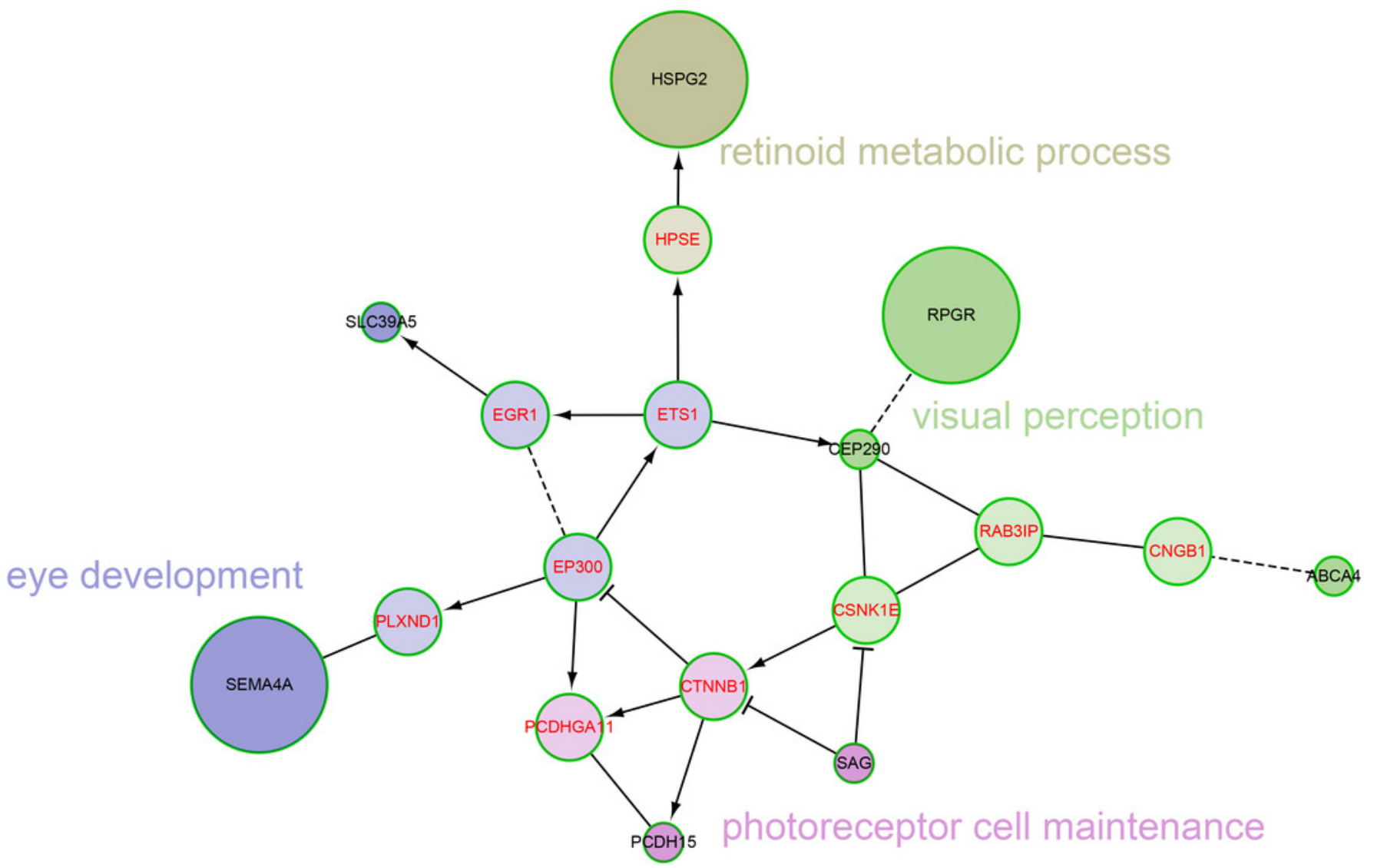

